\title{
Relevansi konsep pemikiran pendidikan dan kebudayaan George S. Counts Dan Ki Hajar Dewantara dengan kompetensi peserta didik
}

\author{
Sekar Purbarini Kawuryan ${ }^{\text {a, }}$ 1* $^{*}$ \\ a Program Studi Pendidikan Guru Sekolah Dasar, Fakultas Ilmu Pendidikan, Universitas Negeri \\ Yogyakarta, Sleman, Indonesia \\ ${ }^{1}$ sekarpurbarini@uny.ac.id \\ *korespondensi penulis
}

\begin{tabular}{ll}
\hline Informasi Artikel \\
\hline Sejarah artikel & \\
Diterima & $: 19-11-2018$ \\
Revisi & $: 20-03-2019$ \\
Dipublikasikan & $: 31-10-2019$ \\
\hline
\end{tabular}

ABSTRAK
Penelitian ini bertujuan untuk mengontekstualisasikan pemikiran dua
tokoh di abad 19 tentang pendidikan dan kebudayaan serta menemukan
relevansi pemikiran tersebut dengan kompetensi peserta didik di abad 21.
Penelitian ini merupakan kajian studi pustaka dengan menggunakan
pendekatan analisis isi. Data dianalisis secara kualitatif dengan
pendekatan induktif. Konsep pemikiran kedua tokoh saling berkaitan
khususnya tentang empat poin pokok, yaitu tujuan pendidikan, fungsi
pendidikan, proses pendidikan, dan peran pendidik. Konsep pemikiran
tersebut masih relevan jika dikontekstualisasikan dengan kompetensi
peserta didik di abad 21. Abad 21 menghendaki peserta didik memiliki
keterampilan berpikir kritis, pemecahan masalah, dan kolaborasi. Tujuan
pendidikan dipandang sebagai cara mengekspresikan peradaban yang
dilayani dan mengusahakan kebudayaan yang berasas keadaban.
Peradaban yang akan dilayani peserta didik di abad 21 adalah perpaduan
pengetahuan, pemikiran, keterampilan inovasi, media, literasi Teknologi
Informasi dan Komunikasi (TIK), dan pengalaman kehidupan nyata.
Untuk itu diperlukan peran optimal pendidik dalam memvariasikan
proses pembelajaran dengan menggunakan berbagai metode sehingga
pendidikan dapat menjalankan fungsinya untuk mengatasi krisis sosial
dan ketertinggalan budaya, sehingga mampu mempertinggi derajat
kemanusiaan. Pendidikan juga harus selalu mewariskan kebudayaan
dalam setiap prosesnya agar peserta didik memiliki keluhuran budi.
ABSTRACT

Kata kunci:

Pendidikan

Kebudayaan

George S. Counts

Ki Hajar Dewantara

Kompetensi peserta didik

Abad 21

Keywords:

Education

Culture

George S. Counts

Ki Hajar Dewantara, competency

21 st century
This research aims to contextualize the thoughts of two figures in the 19th century about education and culture and to find out the relevance with students in the 21 st century. This research conducted a literature study with content analysis approach. Data are analyzed qualitatively with an inductive approach. The research results show that the concepts of thought of the two figures are interrelated, especially about the four main points, namely the purpose of education, the function of education, the educational process, and the role of educators. The concept of thought is still relevant if contextualized with the competence of students in the $21 \mathrm{st}$ century. The 21 st century requires students to have critical thinking skills, problem-solving, and collaboration. The purpose of education problemsolving as a way of expressing the civilization served and cultivating a culture based on civilization. The civilization that will be served by students in the 21 st century is a blend of knowledge, thought, innovation skills, media, information and communication technology literacy (ICT), and real-life experiences. For this reason, the optimal role of educators learning process using various methods to overcome social crises and cultural backwardness, to enhance humanity. Education also must always transmit the culture in every process so that students have nobility. 



\section{Pendahuluan}

Diskusi tentang keterampilan dan kompetensi abad ke-21 di jenjang pendidikan dasar dianggap penting atas dasar pengakuan terhadap kondisi yang berubah dalam kehidupan pribadi, sosial, dan profesional (Chalkiadaki, 2018). Sistem pendidikan saat ini telah dirancang dengan ide yang jelas tentang kemampuan akademik dan profesional yang sesuai dengan kemauan revolusi industri. Pertumbuhan pengetahuan, industri, manajemen, dan teknologi komunikasi informasi (TIK) berefek signifikan pada lembaga pendidikan sehingga mengubah kondisi pembuat kebijakan dan pendidik serta konsep menantang yang dianggap biasa seperti pengetahuan, informasi, dan kemampuan (Zajda, 2010).

Negara-negara berinvestasi dalam pendidikan dengan harapan bahwa hal itu akan berkontribusi pada kesejahteraan ekonomi dan keberlanjutan jangka panjang. Aspek lain dari pendidikan terkait dengan isuisu perkembangan manusia dan sosial penting jika dikaitkan dengan kebutuhan masyarakat yang lebih mendasar di mana reorientasi prioritas merupakan kebutuhan yang mendesak (Senge, 2010). Pendidikan lebih "utilitarian dari pada budaya" (Hargreaves, Lieberman, Fullan, \& Hopkins, 2010).

Delors (1996) mempresentasikan empat pilar yang direkomendasikan untuk pendidikan abad baru: "belajar untuk mengetahui", "belajar untuk melakukan", "belajar untuk hidup bersama" dan "belajar untuk menjadi". Akan tetapi, Zajda (2010) menyatakan keprihatinan bahwa setelah satu dekade terhitung dari publikasi laporan, konsep "belajar menjadi" tetap sulit untuk dipahami dan secara efektif berlangsung di ruang kelas.

Pendidikan masa sekarang dan masa depan perlu menetapkan tujuan baru yang berfokus pada pengembangan identitas kewarganegaraan nasional dan global yang bertanggung jawab dan efektif pada siswa, dengan semua pengetahuan, keterampilan, dan sikap yang diperlukan (Zajda, 2010). Selain itu, pendidikan kontemporer memiliki tantangan baru, yaitu pengembangan generasi yang mampu memahami aspek interdependensi dan berkembang di dalamnya yang disebut generasi "warga sistem" (Hargreaves et al., 2010). Dalam kondisi ini, abad 21 melahirkan pendekatan baru tentang keterampilan yang penting diberikan kepada siswa untuk dapat sukses secara akademik dan non akademik.

Kesadaran global di abad 21 semakin mendapat perhatian berdasarkan pengakuan atas perkembangan dunia sebagai desa global di mana warga negara dipengaruhi oleh isuisu saling ketergantungan (West Virginia Department of Education, 2009). Perkembangan isu-isu global saat ini menjadi wacana yang semakin penting di tengah kondisi global yang semakin saling ketergantungan satu sama lain. Masalah yang terjadi di suatu negara dengan sangat cepat bisa menjadi isu global. Interdependensi masyarakat global ini harus disikapi sebagai peluang yang terbuka bagi perkembangan dunia pendidikan suatu negara. Perkembangan ekonomi, budaya, dan politik akibat dari globalisasi mempengaruhi dunia secara meluas dan mempengaruhi cara pandang warga negara melihat perkembangan tersebut. Kebutuhan dan kesempatan warga yang menjadi tren saat ini di abad 21 untuk menjawab tantangan-tantangan kemelekan dan keterlibatan warga negara yang signifikan dan kompleks. Tantangan tersebut membutuhkan lebih daripada pengetahuan tradisional warganegara dalam politik sebab tantangannya berbeda dengan sebelum abad 21 di mana dunia belum memasuki fase digital. Masyarakat saat ini ditantang tidak hanya mampu terlibat dan menyelesaikan masalah lokal dan nasional, namun juga terkait isu-isu global. Tantangan lainnya adalah arus informasi yang begitu deras mengalir memuat masyarakat harus menentukan informasi mana yang dapat dipercaya dan dijadikan dasar keterlibatannya.

Sistem pendidikan di dunia, terutama di Indonesia sekarang ini menghadapi tugas

Jurnal Civics: Media Kajian Kewarganegaraan |177 
yang rumit dalam mempersiapkan peserta didik untuk dunia yang terus berkembang menjadi komunitas global di mana barang, jasa, modal, ide, teknologi, dan orang mengalir bebas melintasi batas-batas nasional. Kekuatan utama globalisasi, yang meliputi saling ketergantungan ekonomi, semakin pentingnya organisasi politik dan ekonomi internasional, dan peningkatan imigrasi dan migrasi yang cepat, adalah kenyataan yang telah menyebabkan banyak komunitas akademik di bidang kajian pendidikan menyerukan interpretasi kewarganegaraan yang lebih global untuk menanggapi beragam perubahan tersebut (Banks, 2004; Barbules \& Torres, 2000; Castle, 2004; Heater, 2000; Morais \& Ogden, 2011; Oxfam, 2006; Rapoport, 2010). Salah satunya adanya dukungan oleh kesadaran budaya dan ekspresi yang dipandang sebagai langkah pertama (European Council, 2006) sebelum mencapai tingkat mampu menghargai nilai berbagai budaya (Heinrichs, 2016) dan membangun hubungan lintas budaya yang disengaja (NTCE, 2007).

Berkaitan dengan uraian di atas, tulisan ini bertujuan mengkontekstualisasikan pemikiran dua tokoh di abad 19 tentang pendidikan dan kebudayaan serta menemukan relevansi pemikiran tersebut dengan kompetensi peserta didik di abad 21 .

\section{Metode}

Penelitian ini merupakan kajian studi pustaka dengan menggunakan pendekatan analisis isi. Sumber data dalam penelitian ini berupa sumber primer dan sumber sekunder. Sumber primer meliputi kumpulan karya $\mathrm{Ki}$ Hajar Dewantara, khususnya dalam buku, "Ki Hajar Dewantara Bagian Pertama; Pendidikan" dan George S. Counts dalam tulisannya "Dare the Schools Build New Social Order? Sumber sekunder berupa tulisan atau karya orang lain tentang George S. Counts dan Ki Hajar Dewantara

Pengumpulan data dilakukan dengan teknik library research. Data dianalisis secara kualitatif dengan pendekatan induktif. Unit analisis meliputi data dari pemikiran kedua tokoh tentang konsep pendidikan dan kebudayaan.

\section{Hasil dan Pembahasan}

\section{Konsep Pemikiran Pendidikan dan Kebudayaan Perspektif George S. Counts}

Sebuah pernyataan yang jelas tentang perlunya keterlibatan pendidik dalam menyelesaikan masalah sosial dibuat oleh George S. Counts (1889-1974) dalam "Dare the Schools Build New Social Order?” yang diterbitkan pada tahun 1932. Counts berusaha mengembangkan studi sosial pendidikan sebagai keseimbangan terhadap peningkatan penekanan pada studi psikologi dan anak dan untuk memajukan pemahaman pendidikan sebagai lembaga yang penting bagi reformasi sosial (Lagemann, 1992). Pandangannya terus relevan dengan masalah pendidikan saat ini dan pantas untuk diaplikasikan kembali. Analisis teori pendidikan Counts berguna dalam mengklarifikasi beberapa tema yang menjadi fokus utama para filsuf rekonstruksi kontroversial. Counts telah berkontribusi besar terhadap pendidikan Amerika.

Pendidikan adalah salah satu obat yang tidak pernah gagal untuk setiap orang sakit yang menjadi subjeknya, apakah itu kejahatan, perang, kemiskinan, kekayaan, ketidakadilan, pemerasan, korupsi politik, kebencian ras, konflik kelas, atau hanya dosa asal saja (Counts, 1932). Rekonstruksi masyarakat secara umum dapat dilakukan melalui sekolah.

Counts menolak pendapat pendidikan progresif yang mencoba untuk memisahkan anak dari dunia yang hanya memberikan sedikit peluang keterlibatan sosial, dan mengisolasi anak. Tugas sekolah adalah membentuk sikap, mengembangkan minat, dan bahkan memaksakan ide." Sekolah seharusnya mengawal tumbuh kembang dan pencapaian anak dengan menempatkannya di dunia sendiri. Salah satu tragedi terbesar dari masyarakat kontemporer menurut terletak pada kenyataan bahwa anak menjadi semakin terisolasi dari kegiatan serius orang dewasa (Counts, 1932). Counts khawatir bahwa sistem pendidikan, di semua tingkatan, gagal untuk membekali manusia, baik kognitif maupun perilaku, untuk menghadapi 
perubahan yang terjadi di kawasan budaya atau kehidupan kualitatifnya Isolasi semacam itu merupakan konsekuensi wajar yang tak terhindarkan dari tumbuhnya tatanan sosial yang semakin berkembang. Situasi seperti ini adalah hasil dari masyarakat yang digerakkan oleh tidak adanya cita-cita yang besar dan akibatnya dikorbankan oleh bentuk kegilaan manusia yang paling mengerikan, yaitu perjuangan demi keuntungan pribadi (Counts, 1932). Pendidikan diperlukan untuk merumuskan filsafat pendidikan yang dapat mempersiapkan para pendidik untuk mengatasi krisis sosial dan ketertinggalan budaya dengan merekonstruksi gagasan, keyakinan, dan nilai-nilai dalam kondisi yang berubah (Gutek, 1974). Oleh karena itu guru memegang posisi sebagai ujung tombak pengambil langkah pertama dalam transformasi sekolah.

Pendidikan selalu mengungkapkan konsepsi peradaban. Pendidikan tidak pernah dapat menjadi proses yang sepenuhnya otonom, terlepas dari waktu, tempat, dan dilakukan sesuai dengan hukumnya sendiri. Ini adalah bagian integral dari peradaban sebagai ekonomi atau sistem politik. Tujuan pendidikan yang dipahami sebagai cara untuk membebaskan atau memperbudak pikiran, adalah ekspresi dari peradaban yang dilayaninya (Gutek, 1974). Meskipun semua program pendidikan di dunia saat ini, termasuk kita sendiri, harus merangkul konsepsi kemanusiaan bersama, tidak ada program yang secara keseluruhan harus dianggap sebagai artikel ekspor baik dengan atau tanpa dukungan dolar atau senapan mesin.

Para guru harus dengan sengaja meraih kekuasaan dan memanfaatkannya untuk membentuk kurikulum dan prosedur sekolah. Cara ini akan mempengaruhi sikap sosial, cita-cita, dan perilaku generasi yang akan datang (Counts, 1932). Kurikulum mencakup semua jenis kegiatan dalam pembelajaran yang dilakukan dalam tanggung jawab sekolah sesuai dengan tujuan sekolah
(Doğanay, 2012). Dalam praktiknya, kurikulum terdiri dari sejumlah rencana, dalam bentuk tertulis dan berbagai lingkup, yang menggambarkan pengalaman belajar yang diinginkan. Kurikulum sekolah harus mengembangkan komitmen untuk belajar yang menyenangkan dan sebagai sarana untuk pencapaian tertinggi (optimal) untuk semua siswa (White, 2004). Kurikulum pendidikan di sekolah harus membantu siswa memperoleh dan belajar menggunakan pengetahuan, keterampilan, nilai-nilai dan sikap yang membantu mereka menjadi warga negara yang aktif yang dibutuhkan dalam masyarakat demokratis.

Guru seharusnya tidak menggunakan dalih atau kesopanan palsu untuk melakukan hal tersebut tidak mengatakan bahwa itu dilakukan hanya untuk mengajarkan kebenaran. Hal tersebut dilakukan untuk kepentingan umum. Para guru memiliki kewajiban sosial yang berat untuk melindungi dan memajukan kepentingan-kepentingan itu. Dalam menguraikan program pendidikan yang demokratis, Counts (1932) menekankan dua tujuan utama yakni pertama, pengembangan kebiasaan demokrasi, disposisi, dan loyalitas, serta kedua, perolehan pengetahuan dan wawasan bagi partisipasi yang cerdas dari masyarakat demokrasi (Gutek, 1974).

Dalam konteks ini, guru menempati posisi yang relatif unik di masyarakat. Profesi ini harus merangkul para ilmuwan dan ulama dari pangkat tertinggi, dan juga guru-guru lainnya yang bekerja di semua tingkat sistem pendidikan. Counts berpendapat sangat tidak masuk akal ketika guru bertindak secara egois atau ceroboh seperti yang dinyatakan orangorang "praktis", yaitu para politisi, para pemodal, kaum industrialis (Counts, 1932). Jika semua fakta ini diperhitungkan, alih-alih menghindari kekuasaan, profesi tersebut sebaiknya mencari kekuatan dan kemudian berusaha menggunakan kekuatan itu secara penuh dan bijaksana demi kepentingan rakyat.

Dalam menegaskan nilai-nilai demokratis dan ekualitarian, Counts mendorong pendidik untuk menekankan bidang warisan budaya 
yang mendorong berbagi pengalaman atau kegiatan kerja sama. Kurikulum harus mencakup bidang pengetahuan sosial yang luas dan teknologi harus menyelidiki masalah nyata dari kehidupan modern (Gutek, 1974). Guru harus siap untuk berdiri di atas kaki dan ide-idenya untuk mendapatkan dukungan dari massa rakyat. Pendidikan sebagai kekuatan regenerasi sosial harus berbaris bersama dengan kekuatan sosial yang tersedia dan mengkreasikan tatanan sosial (Counts, 1932, p. 283). Para guru harus menjembatani kesenjangan antara sekolah dan masyarakat. Guru juga memainkan beberapa bagian dalam pembentukan tujuan-tujuan bersama yang mengikat sekolah dan masyarakat secara bersama-sama. Peliknya masalah di masa depan menurut prediksinya tidak bisa diselesaikan oleh pendidikan di sekolah saja, namun lebih luas menyangkut kelas serta kehidupan sekolah dan, di luar, komunitas (kota, desa, atau sekolah dan komunitas) (Beutel, 2012).

Permasalahan pendidikan tidak sepenuhnya bersifat intelektual. Sekolah yang efektif harus menjadi pusat bangunan, dan bukan hanya untuk kontemplasi peradaban (Counts, 1932). Hal ini tidak dimaknai sama dengan usaha guru untuk mempromosikan reformasi tertentu melalui sistem pendidikan. Akan tetapi, guru harus menyampaikan visi tentang kemungkinan-kemungkinan yang berpeluang muncul dan berusaha untuk mendapatkan loyalitas dan antusiasme dalam merealisasikan visi tersebut.

Sekolah hanyalah salah satu dari banyak lembaga budaya (Gutek, 1975). Oleh karena itu, pendidik harus selalu sadar perubahan fungsi dan struktur masyarakat yang menentukan tugasnya. Counts menyatakan bahwa sebagai anggota masyarakat, berpartisipasi dalam budaya melalui penggunaan instrumen budaya, dapat membantu tumbuh kembang anak melalui pengalaman. Sebagai seorang peserta budaya, anak dikenakan oleh budaya dan pada gilirannya membebani budaya.

Salah satu cara yang dapat dilakukan untuk mengembangkan budaya demokratis dilakukan dengan pengembangan kultur sekolah yang humanis (Aloni, 2011; Suyato, 2016; Veugelers, 2011). Upaya pengembangan kultur sekolah yang humanis dilakukan diantaranya pertama, dengan pengembangan kepribadian siswa a" dan bertindak dalam situasi yang sulit dan mengambil solusi sederhana (Aloni, 2011). Kedua, Iklim sosial akan keamanan dan keadilan. Ketiga, yakni dialog yang memberdayakan. Keempat, yakni pendekatan komunitas dan keterlibatan sosial. Kelima, Infrastruktur fisik yang nyaman, aman, dan indah.

\section{Konsep Pemikiran Pendidikan dan Kebudayaan Perspektif Ki Hajar Dewantara}

Pendidikan "menuntun segala kekuatan kodrat yang ada pada anak-anak, agar mereka sebagai manusia dan sebagai anggota masyarakat dapat mencapai keselamatan serta kebahagiaan yang setinggi-tingginya" (Dewantara, 2011, hal. 20). Pendidikan bagi Ki Hajar Dewantara berarti upaya untuk memajukan perkembangan budi pekerti (kekuatan batin), pikiran (intelektual), dan jasmani peserta didik (Kumalasari, 2015). Peserta didik hanya dapat berkembang ketika pendidikan dilakukan tanpa paksaan dan tanpa perintah.

Pendidikan dan pengajaran merupakan laku yang bersifat "kulturil" (Dewantara, 1977, hal. 318). Arti kebudayaan atau kultur kemanusiaan adalah semua benda buatan manusia, baik benda batin maupun benda lahir, yang muncul karena kematangan budi manusia tersebut. Kematangan budi tersebut menghasilkan kehalusan peranan (moril), kecerdasan pikiran, dan kekuatan kehendak. Ketiganya merupakan "trisakti" manusia. Kultur juga dapat dimaknai bahwa hidup manusia selalu mengalami kemajuan. Sifat manusia pada zaman sekarang berbeda dengan nenek moyang pada zaman purbakala (Dewantara, 1977, hal. 319).

Berkaitan dengan pemaknaan ini, pekerjaan kultural adalah semua usaha untuk mempertinggi derajat kemanusiaan. 
Kebudayaan dalam perguruan bertujuan untuk memelihara, memajukan hidup, memperbaiki jenis, dan faedah hidup anak-anak didik (Dewantara, 1977, hal. 322). Sifat pendidikan dan pengajaran yang kulturil mengusahakan bertumbuhnya budi yang sebaik-baiknya, dengan mencerdaskan pikiran, perasaan, dan kemauan (Dewantara, 1977, hal. 322). Ki Hajar Dewantara memandang bahwa perguruan saat ini hanya mementingkan pendidikan pikiran, dan kurang memperhatikan pendidikan perasaan dan kemauan.

Sementara itu pendidikan perasaan terbagi menjadi dua jenis sesuai maksud dan tujuannya, yaitu pendidikan ethic (pendidikan kehalusan hidup kebatinan/pendidikan moril) dan pendidikan aesthetic (pendidikan kesenian). Pendidikan ethic dapat mengembangkan perasaan anak-anak, seperti perasaan religius, sosial, dan individual yang semuanya berarti kecintaan terhadap agama, hidup kemanusiaan, dan dirinya sendiri (Dewantara, 1977, hal. 323). Sebagai tindak lanjut pendidikan ethic, pendidikan aesthetic bertujuan menghaluskan perasaan terhadap segala benda lahir yang bersifat indah. Aesthetic mengajarkan segala kesenian, seperti seni kata, seni suara, seni menggambar, sandiwara, wayang, dan seni tari. Pendidikan aesthetic membantu anakanak memperoleh kecerdasan yang luas dan sempurna dari roh, jiwa, dan budinya sehingga keluhurannya sebagai manusia dapat meningkat (Dewantara, 1977, hal. 324). Sifat pendidikan kultural yang ketiga adalah pendidikan kemauan. Pemberian kesempatan kepada anak untuk berbuat, tidak hanya berfikir. Anak-anak perlu dibiasakan mewujudkan kemauannya, yaitu berbuat, bertenaga, dan bekerja. Bangsa-bangsa Timur memiliki adat untuk menguatkan kemauan itu antara lain dengan berkuasa, berjalan, dan bertapa (Dewantara, 1977, hal. 324).

Ki Hajar Dewantara menyatakan dasardasar dan garis besar tuntunan kebijaksanaan yang harus diperhatikan saat terjadi pertukaran kebudayaan dengan bangsa lain (Dewantara, 1977, hal. 227). Bahan-bahan dan benda-benda kebudayaan yang perlu atau baik saja yang diambil untuk hidup dan penghidupan rakyat, serta menolak hal-hal yang bersifat merugikan. Untuk memudahkan, menyelamatkan, dan menyempurnakan masuknya berbagai bahan dan benda kebudayaan tersebut, perlu mengutamakan asas "trikon," yaitu kontinuitet, konvergensi, dan konsentrisitet (Dewantara, 1977, p. 228).

Pertama, asas kontinuitet berarti garis hidup di zaman sekarang harus merupakan lanjutan dari hidup di zaman sebelumnya, jangan berupa pengulangan atau tiruan dari bangsa lain. Kedua, asas konvergensi artinya keharusan untuk menghindari hidup menyendiri (isolasi) dan untuk bertemu dengan kehidupan bangsa-bangsa lain sedunia. Ketiga, asas konsentrisitet yaitu setelah bersatu dengan bangsa-bangsa lain sedunia, janganlah kehilangan kepribadian dengan tetap menjaga lingkaran konsentris bangsa sendiri.

Cita-cita yang tersirat dalam ketiga asas di atas hendaknya diupayakan dapat dilaksanakan antara lain dengan saluran sistem pendidikan dan pengajaran. Hal ini penting karena pendidikan merupakan tempat persemaian benih-benih kebudayaan bangsa yang seharusnya mengandung unsur-unsur kulturil nasional. Oleh karena itu, siswa di tingkat pendidikan tinggi, yang dimulai dari SMA sampai perguruan tinggi perlu memperoleh bekal yang cukup guna mendekati alam internasional, secara konvergensi (Dewantara, 1977, hal. 228).

Pendidikan yang dilakukan dengan keinsafan, ditujukan ke arah keselamatan dan kebahagiaan manusia, tidak hanya bersifat laku "pembangunan" tetapi juga merupakan "perjuangan" (Dewantara, 1977, hal. 166) Pendidikan berarti memelihara hidup-tumbuh ke arah kemajuan, tidak boleh melanjutkan keadaan kemarin. Pendidikan juga merupakan usaha kebudayaan, berasas keadaban, yaitu

Jurnal Civics: Media Kajian Kewarganegaraan |181 
memajukan hidup agar mempertinggi derajat kemanusiaan.

Sistem pendidikan dan pengajaran bagi anak-anak hendaknya didasarkan pada hidup kemanusiaan, yaitu keluhuran budi dan bersendi pada segala sifat peradaban bangsa dalam arti luas (Dewantara, 1977, hal. 149). Keluhuran budi dan peradaban bangsa tersebut di kalangan gerakan pendidikan dan pengajaran dikenal dengan istilah dasar kebudayaan. Apabila pendidikan dan pengajaran bagi anak-anak telah bersandar pada kebudayaan kebangsaannya sendiri, niscaya segala akar hidup barat yang dapat merusak keselamatan dan kesejahteraan dapat dihindari.

Pemikiran George S. Counts dan Ki Hajar Dewantara tentang Pendidikan dan Kebudayaan serta Relevansinya dengan Kompetensi Peserta Didik di Abad 21

Sebelum membahas keterkaitan pemikirannya, berikut disajikan tabel profil singkat kedua tokoh pendidikan di abad 19.

Tabel Profil Singkat George S. Counts dan Ki Hajar Dewantara

\begin{tabular}{|c|c|c|}
\hline Profil Singkat & George S. Counts & Ki Hajar Dewantara \\
\hline Identitas diri & $\begin{array}{l}\text { Lahir di Amerika } \\
\text { Desember } 1889\end{array}$ & Lahir di Yogyakarta, 18 Mei 1889 \\
\hline Peran dan jabatan & $\begin{array}{l}\text { 1. Filsuf sosial dan pendidikan, } \\
\text { Advokat rekonstruksionis, } \\
\text { 2. Ahli pendidikan di Amerika dan } \\
\text { Rusia, } \\
\text { 3. Presiden Federasi Guru Amerika } \\
\text { tahun 1939-1942, } \\
\text { 4. Anggota Komisi Kebijakan } \\
\text { Nasional tahun 1936-1942, } \\
\text { 5. Pendidik guru di Universitas } \\
\text { Washington Chicago, Yale, dan } \\
\text { Columbia College. }\end{array}$ & $\begin{array}{l}\text { 1. Aktivis organisasi "Budi Utomo" } \\
\text { 2. Pendiri "Indische Partij" } \\
\text { 3. Pendiri "Komite Bumiputera" } \\
\text { 4. Tokoh jurnalistik, } \\
\text { 5. Tokoh perintis kemerdekaan } \\
\text { 6. Anggota harian "de express" } \\
\text { 7. Anggota Harian "Kaoem Muda" }\end{array}$ \\
\hline $\begin{array}{l}\text { Beberapa Karya yang } \\
\text { Dihasilkan }\end{array}$ & $\begin{array}{l}\text { 1. Dare the Schools Build New } \\
\text { Social Order? } \\
\text { 2. The Principles of Education, } \\
\text { 3. Secondary Education and } \\
\text { Industrialism, } \\
\text { 4. The American Road to Culture, } \\
\text { 5. The Social Foundations of } \\
\text { Education, } \\
\text { 6. The Prospects of American } \\
\text { Democracy, } \\
\text { 7. Education and the Promise of } \\
\text { America, } \\
\text { 8. Education and American } \\
\text { Civilization, } \\
\text { 9. Education and the Foundations } \\
\text { of Human Freedom }\end{array}$ & $\begin{array}{ll}\text { 1. Als ik eens Nederlander was } \\
\text { 2. Pendidikan dan Pengajaran } \\
\text { Nasional (Wasita, 1928, (3)) } \\
\text { 3. Kebudayaan dan Pengajaran } \\
\text { dalam Hubungan Antarnegara } \\
\text { (Pusara, 1954, XV(12)) } \\
\text { 4. Pendidikan dan Pengajaran untuk } \\
\text { Seluruh Indonesia (Pusara, 1955, } \\
\text { XVI(10)) } \\
\text { 5. Kultur dan Kunst di dalam } \\
\text { Perguruan (Pusara, 1940, X(8)) }\end{array}$ \\
\hline
\end{tabular}

Sumber: Data yang telah diolah peneliti, 2018.

Kajian terhadap pemikiran George S. tujuan pendidikan, fungsi pendidikan, proses Counts dan Ki Hajar Dewantara pada pendidikan, dan peran pendidik. Poin-poin akhirnya menemukan empat poin pokok, yaitu tersebut tersaji dalam tabel berikut ini. 
Tabel Konsep Pemikiran

\begin{tabular}{|c|c|c|}
\hline Konsep Pemikiran & George S. Counts & Ki Hajar Dewantara \\
\hline Tujuan pendidikan & $\begin{array}{l}\text { Cara mengekspresikan } \\
\text { peradaban yang dilayani }\end{array}$ & $\begin{array}{l}\text { Usaha kebudayaan, berazas } \\
\text { keadaban }\end{array}$ \\
\hline Fungsi pendidikan & $\begin{array}{l}\text { Mengatasi krisis sosial dan } \\
\text { ketertinggalan budaya }\end{array}$ & $\begin{array}{l}\text { Memajukan hidup, mempertinggi } \\
\text { derajat kemanusiaan }\end{array}$ \\
\hline Proses pendidikan & $\begin{array}{l}\text { Transmisi warisan budaya } \\
\text { yang layak kepada anggota } \\
\text { masyarakat yang belum } \\
\text { dewasa. }\end{array}$ & $\begin{array}{l}\text { Berpedoman pada kebudayaan } \\
\text { bangsa sendiri }\end{array}$ \\
\hline Peran pendidik & $\begin{array}{l}\text { Menjembatani kesenjangan } \\
\text { sekolah dan masyarakat }\end{array}$ & $\begin{array}{l}\text { Mengusahakan } \\
\text { budi yang baik }\end{array}$ \\
\hline
\end{tabular}

George S. Counts dan Ki Hajar Dewantara memiliki banyak persamaan dalam memandang pendidikan dan kebudayaan. Tujuan pendidikan dipandang sebagai cara mengekspresikan peradaban yang dilayani. Pendapat Counts tersebut sejalan dengan Ki Hajar Dewantara bahwa pendidikan bertujuan mengusahakan kebudayaan yang berasas keadaban. Peradaban yang akan dilayani peserta didik di abad 21 adalah perpaduan pengetahuan, pemikiran, keterampilan inovasi, media, literasi Teknologi Informasi dan Komunikasi (ICT), dan pengalaman kehidupan nyata dalam konteks mata pelajaran akademis inti (Johnson, 2009). Oleh karena itu peserta didik terlibat dalam lingkungan pembelajaran secara efektif dan mengembangkan keterampilan berpikir kritis, pemecahan masalah, dan kolaborasi. Dengan cara ini, peserta didik dibekali pengetahuan dan keterampilan hidup yang dapat membantu kesuksesannya dalam karir masa depan (Lombardi \& Oblinger, 2007).

Counts memandang fungsi pendidikan adalah mengatasi krisis sosial dan ketertinggalan budaya. Sementara itu, hampir sama dengan Counts, Ki Hajar Dewantara menyatakan bahwa pendidikan berfungsi untuk mempertinggi derajat kemanusiaan. Untuk menjalankan fungsi seperti pendapat dua tokoh ini, peran penting pendidik dapat dioptimalkan dengan menerapkan berbagai variasi metode pembelajaran. Pendidik diharapkan menggunakan strategi inovatif dan teknologi pembelajaran modern sehingga
Sumber: Data yang telah diolah peneliti, 2018 dapat mengintegrasikan pengetahuan dan keterampilan sosial dengan konten pembelajaran. Penerapan pembelajaran berbasis masalah dapat meningkatkan partisipasi dan keterampilan berpikir kritis peserta didik dalam kegiatan kelas (Joyce, Weil, \& Calhoun, 2015). Selain itu, terdapat korelasi yang signifikan antara kegiatan pembelajaran berbasis masalah dan keterampilan berpikir kritis yang dibutuhkan peserta didik pada abad 21(Drew, 2012).

Apabila dicermati berdasarkan proses pendidikan, kedua tokoh memandang pentingnya peran masyarakat dengan budayanya. Counts menyatakan bahwa warisan budaya layak ditularkan kepada peserta didik, sementara Ki Hajar Dewantara memandang proses pendidikan harus berpedoman pada kebudayaan bangsa sendiri. Hal ini penting jika dikontekstualisasikan dengan kompetensi yang harus dimiliki peserta didik di abad 21. Seiring dengan perkembangan teknologi, inovasi ilmiah, peningkatan globalisasi, perubahan tuntutan tenaga kerja, tekanan ekonomi dan perubahan yang cepat dalam persaingan dalam masyarakat saat ini, keterampilan yang dibutuhkan dalam diri peserta didik untuk berkontribusi pada masyarakat dan meningkatkan kesiapan mereka menghadapi abad baru telah didefinisikan ulang (Levy \& Murnane, 2005; Stewart, 2010; Wilmarth, 2010).

Perbedaan keterampilan abad 21 dengan abad sebelumnya terutama terletak pada 
munculnya teknologi informasi dan komunikasi canggih (Shute \& Becker, 2010). Dalam masyarakat informasi, individu diharapkan dapat menyesuaikan diri dengan masyarakat yang kompleks, memilih pengetahuan, menganalisis pengetahuan, dan memanfaatkannya untuk memecahkan masalah kehidupan sehari-hari. Dengan demikian individu harus memiliki keterampilan tingkat tinggi seperti pemikiran analitis, keterampilan antar-pribadi dan organisasi pengetahuan (Velez, 2012). Untuk mewujudkan kompetensi tersebut, penularan warisan kebudayaan bangsa sendiri harus menjadi upaya yang kontinyu sehingga peserta didik memiliki keluhuran budi dalam berproses menjadi individu yang diharapkan seperti uraian di atas.

Perkembangan pesat teknologi menghendaki peran optimal pendidik untuk dapat menjembatani sekolah dengan masyarakat sebagai upaya berkembangnya budi yang baik dari peserta didik. Peserta didik abad ke-21 diharapkan memiliki kompetensi pengarahan diri sendiri dan kemampuan berkolaborasi dengan individu, kelompok, dan mesin (McCoog, 2008) (McCoog, 2008). Oleh karena itu, jejaring sosial yang dibangun di atas gagasan tentang bagaimana orang tahu, harus tahu, dan berinteraksi satu sama lain (Zaidieh, 2012) (Zaidieh, 2012), seyogianya dapat dimanfaatkan oleh pendidik dengan bijak. Jejaring sosial memungkinkan pendidik di sekolah dasar untuk mengintegrasikan teknologi ke dalam proses belajar mengajar. Selain itu, media ini juga dapat menyadarkan pendidik secara sosial tentang permasalahan para siswanya.

Setiap kemajuan teknologi menghadirkan konstruksi teoretis dan wawasan realistis dalam pengembangan dan peningkatan pengetahuan, keterampilan, dan sikap di antara siswa dan guru (Leon-Abao, Boholano, \& Dayagbil, 2015). Sebagaimana diungkapkan oleh Boholano (2013), TIK tidak secara otomatis meningkatkan pengajaran dan pembelajaran, guru harus melakukan sesuatu untuk memotivasi peserta didik. Peningkatan proses belajar mengajar tergantung pada strategi yang digunakan oleh guru. Teknologi akan membantu para guru memfasilitasi pengajaran yang efektif.

\section{Simpulan}

George S. Counts dan Ki Hajar Dewantara adalah dua tokoh pendidikan yang dilahirkan pada tahun yang sama di dua negara yang berbeda, yaitu Amerika Serikat dan Indonesia. Konsep pemikiran kedua tokoh ini tentang pendidikan dan kebudayaan memiliki persamaan, yaitu dalam memaknai tujuan pendidikan, fungsi pendidikan, proses pendidikan, dan peran pendidik. Konsep pemikiran tersebut masih relevan jika dikontekstualisasikan dengan kompetensi peserta didik di abad 21. Abad 21 menghendaki peserta didik memiliki keterampilan berpikir kritis, pemecahan masalah, dan kolaborasi. Tujuan pendidikan dipandang sebagai cara mengekspresikan peradaban yang dilayani dan mengusahakan kebudayaan yang berasas keadaban. Peradaban yang akan dilayani peserta didik di abad 21 adalah perpaduan pengetahuan, pemikiran, keterampilan inovasi, media, literasi Teknologi Informasi dan Komunikasi (ICT), dan pengalaman kehidupan nyata. Untuk itu diperlukan peran optimal pendidik dalam memvariasikan proses pembelajaran dengan menggunakan berbagai metode sehingga pendidikan dapat menjalankan fungsinya untuk mengatasi krisis sosial dan ketertinggalan budaya, sehingga mampu mempertinggi derajat kemanusiaan. Pendidikan juga harus selalu mewariskan kebudayaan dalam setiap prosesnya agar peserta didik memiliki keluhuran budi.

\section{Referensi}

Aloni, N. (2011). Humanistic education: From theory to practice. In W. Veugelers (Ed.), Education and humanism. Linking autonomy and humanity (hal. 35-46). Roterdam/ Boston/ Taipe: Sense Publisher. 
Banks, J. A. (2004). Introduction: Democratic citizenship education in multicultural societies. In J. A. Banks (Ed.), Diversity and citizenship education: Global perspectives (hal. 17-48). San Francisco, CA: Jossey-Bass.

Barbules, N. C., \& Torres, C. A. (2000). Globalization and education: An introduction. In N. C. Barbules \& C. A. Torres (Ed.), Globalization and Education: Critical Perspectives (hal. 127). New York, NY: Routledge.

Beutel, W. (2012). Developing civic education in schools: The Challenge. In Muray Print \& D. Lange (Ed.), School, curriculum and civic education for building democratic citizens (hal. 7-18). Roterdam, Boston, Taipe: Sense Publishers.

Castle, S. (2004). Migration, citizenship, and education. In J. A. Banks (Ed.), Diversity and citizenship education: Global perspectives. San Francisco, CA: JosseyBass.

Chalkiadaki, A. (2018). A systematic literature review of 21 st century skills and competencies in primary education. International Journal of Instruction, 11(3), 1-16. https://doi.org/10.12973/iji.2018.1131a

Counts, G. S. (1932). Dare the schools build a new social order? Illinois: Southern Illinois University Press.

Delors, J. (1996). Learning: the treasure within. Report to UNESCO of the International Commission on Education for the twenty-first-Century, Paris UNESCO 1996. Internationales Jahrbuch der Erwachsenenbildung. https://doi.org/10.7788/ijbe.1996.24.1.2 53

Dewantara, K. H. (1977). Karya Ki Hadjar Dewantara. Bagian pertama: Pendidikan. Yogyakarta.

Dewantara, K. H. (2011). Bagian pertama: pendidikan. Yogyakarta: Majelis Luhur Persatuan Tamansiswa.

Doğanay, A. (2012). A curriculum framework for active democratic citizenship education. In Murray Print \& D. Lange
(Ed.), School, curriculum and civic education for building democratic citizens (hal. 19-39). Roterdam, Boston, Taipe: Sense Publisher.

Drew, S. V. (2012). Open up the ceiling on the common core state standards: Preparing s t udents for 21st-century literacy-now. Journal of Adolescent and Adult Literacy, 56(4), 321-330. https://doi.org/10.1002/JAAL.00145

European Council. (2006). Recommendation of the European Parliament and the Council on key competencies for lifelong learning. Official Journal of the European Union, (March 2002), 10-18. Diambil dari http://eurlex.europa.eu/LexUriServ/LexUriServ.d o?uri=OJ:L:2006:394:0010:0018:en:PD $\mathrm{F}$

Gutek, G. L. (1974). Philosophical alternatives in education. Ohio: Charles E. Merrill Publishing Company.

Hargreaves, A., Lieberman, A., Fullan, M., \& Hopkins, D. (Ed.). (2010). Second international handbook of educational change (Vol. 23). Dordrecht Heidelberg London New York: Springer. https://doi.org/10.1017/CBO978110741 5324.004

Heater, D. (2000). Does cosmopolitan thinking have a future? Review of International Studies, 26(5), 79-197. https://doi.org/10.1017/S026021050000 1790

Heinrichs, C. (2016). Exploring the influence of 21 st century skills in a dual language program: a case study. International Journal of Teacher Leadership, 7(1), 3757.

Johnson, P. (2009). The 21st century skills movement. Educational Leadership, 67(1), 11.

Joyce, B., Weil, M., \& Calhoun, E. (2015). Model of teaching (9th ed.). New York: Allyn and bacon a Pearson Education Company.

Kumalasari, D. (2015). Konsep pemikiran Ki Hadjar Dewantara dalam pendidikan taman siswa (tinjauan humanis-religius). Istoria, 8(1), 47-59. 
Lagemann, E. C. (1992). Prophecy or profession? George S. Counts and the social study of education. American Journal of Education, 100(2), 137-165.

Leon-Abao, E. de, Boholano, H. B., \& Dayagbil, F. T. (2015). Engagement to social networking: challenges and opportunities to educators. European Scientific Journal June, 11(16), 173191.

Levy, F., \& Murnane, R. J. (2005). How computerized work and globalization shape human skill demands (MIT-IPC05-006 August). Cambridge, MA.

Lombardi, B. M. M., \& Oblinger, D. G. (2007). Authentic learning for the 21st Century: An Overview. Learning, 1(May), 1-7. Diambil dari http://alicechristie.org/classes/530/EduC ause.pdf

McCoog, I. J. (2008). 21 ST century teaching and learning. Diambil dari eric.ed.gov/PDFS/ED502607.pdf

Morais, D. B., \& Ogden, A. C. (2011). Initial development and validation of the global citizenship scale. Journal of Studies in International Education, 15(5), 445466. https://doi.org/10.1177/1028315310375 308

NTCE. (2007). 21st century literacies. Illinois.

Oxfam. (2006). Education for global citizenship: A guide for schools. Oxfam GB.

Rapoport, A. (2010). We cannot teach what we don't know: Indiana teachers talk about global citizenship education. Education, Citizenship and Social Justice, 5(3), 179-190. https://doi.org/10.1177/1746197910382 256

Senge, P. M. (2010). Education for an interdependent world: developing systems citizens. In A. Hargreaves, A. Lieberman, M. Fullan, \& D. Hopkins (Ed.), Second international handbook of educational change (hal. 131-152). Dordrecht Heidelberg London New
York: Springer.

Shute, V. J., \& Becker, B. J. (Ed.). (2010). Innovative assessment for the 21st century: supporting educational needs. New York Dordrecht Heidelberg London: Springer.

Stewart, V. (2010). A Classroom as wide as the world. In H. H. Jacobs (Ed.), Curriculum 21: essential education for a changing world (hal. 97-114). Alexandria, VA: ASCD.

Suyato. (2016). Belajar demokrasi di sekolah: Reorientasi pendidikan dan pengembangan kultur sekolah yang humanis. Jurnal Civics: Media Kajian Kewarganegaraan, 13(1), 83-95.

Velez, A. (2012). Preparing students for the future - 21st century skills. University of Southern California.

Veugelers, W. (Ed.). (2011). Education and humanism. Linking autonomy and humanity. Roterdam, Boston, Taipe: Sense Publishers. https://doi.org/10.1017/CBO978110741 5324.004

White, J. (Ed.). (2004). Rethinking the school curriculum. Values, aims and purposes. London and New York: Routledge Falmer. https://doi.org/10.4324/9780203618523

Wilmarth, S. (2010). Five socio-technology trends that change everything in learning and teaching. In H. H. Jacobs (Ed.), ASCD (Penerj.), Curriculum 21: essential education for a changing world (hal. 80-97). Alexandria, VA.

Zaidieh, A. J. Y. (2012). The use of social networking in education: challenges and opportunities. World of Computer Science and Information Technology Journal (WCSIT), 2(1), 18-21.

Zajda, J. (Ed.). (2010). Global pedagogies schooling for the future. Global Pedagogies. Springer Dordrecht Heidelberg London New York: Springer. https://doi.org/10.1007/978-90-4813617-9 